\title{
Hack the School: A Creative Toolkit to Transform School Spaces
}

\author{
Sílvia Sasot and Esther Belvis
}

\begin{abstract}
The 'Hack the School' project provides school communities a guided experience to support the transformation of their learning spaces. The aim is to foster change through a comprehensive and co-creative approach facilitating the transition from traditional uses of space to innovative ones with the concept of wellbeing as primary agency. A conceptual framework based on seven principles-welcome, belonging, communication, cooperation, diversity, movement and transduction - and an applied creative toolkit equip the process and provide a unique and novel perspective to the topic of innovative learning environments. Thus, the project channels the emerging needs regarding educational spaces challenging the current regulations that the public administration applies in Spain and initiates a dialogical collaboration between the field of education and architecture. The challenge open to all schools and funded by the Jaume Bofill Foundation received over 170 proposals in the Catalan context, where 30 schools were selected and are now becoming effective 'hackers'.
\end{abstract}

\section{Introduction: Schools, Spaces, Trends and Legislation in Spain}

Innovation trends in education often embrace a 'frantic change' approach which is mainly associated with improved performance and constant adaptability to change. In this innovation paradigm where production and efficiency support emerging ideas, education space transformation in Spain has been restricted and mainly associated with the incorporation of information and communications technology (ICT) (Adell \& Castañeda, 2012). However, although ICT can be conceived as a trigger for many emerging challenges in education, the truth is that educational improvement involves

\author{
S. Sasot $(\bowtie)$ \\ Universitat Ramon Llull, Barcelona, Spain \\ e-mail: silsasot@gmail.com \\ E. Belvis \\ Universitat Autònoma de Barcelona, Barcelona, Spain \\ e-mail: ebelvis.pons@gmail.com
}

W. Imms and T. Kvan (eds.), Teacher Transition into Innovative Learning Environments, https://doi.org/10.1007/978-981-15-7497-9_24 
a conglomerate of interrelated aspects well beyond ICT, and all need to be considered and addressed. Current emerging pedagogies focus on the search for optimal methods and formulas to respond to the standards proposed by the educational systems and other international bodies, such as the Organisation for Economic Co-operation and Development (OECD). The OECD's seven principles of learning have become a key driver for the introduction of the concept of innovative learning environments (Hanna \& David, 2013).

Despite the value of those principles and their significance in establishing new approaches for both practitioners and policy-makers, the fact is that the conceptualization and possibilities for innovative learning environments (ILE) are subjected to a myriad of contextual needs and regulations. There are deep patterns of thinking related to traditional educational buildings design: classroom, corridors, table-chair, teacher desk, teacher room, etc. There is a need to observe and problematize, both subjectively and objectively, the patterns of thinking that go into designing school buildings and educational spaces (particularly in Spain where the issues related to school architecture are often quite conventional). Rather than responding to diversity, the predominant paradigm of school building design trends towards homogenization (see catalan regulations for designing Public Schools: http://ens enyament.gencat.cat/web/.content/home/departament/publicacions/monografies/cri teris-construccio-edificis-centres-publics/criteris_construccio_edificis_centres_d ocents_publics.pdf).

\section{A Variety of Needs?}

In Spain the government has stipulated institutional categories that must guide the design of educational sites. This includes regulations on the types and sizes of spaces that should be included in a building. When the government regulates school architecture to this degree, it is hard to achieve diversity of approaches, as government requirements become the norm. From an objective perspective, and in order to steer away from homogenization, it is necessary to explore the key aspects of learning environments from a wider perspective.

In the current system in Spain a blueprint is provided to the designers which defines the measurements of classrooms and resembles a factory design (production) rather than a community design (co-living). Architects receive an official drawing with rows of chairs looking at the blackboard as a recommendation from the document 'criteria for the construction of new buildings for public educational centers' Only 'productive' spaces are considered, i.e. where one teacher leads one group of students; shared areas and community spaces are not considered. The regulations have been revised only twice since the Spanish Constitution was signed in December 1978 (March 2010 and June 1991), but these still reflect the political concerns of the Spanish Transition 1975-78, and Franco's dictatorship. It is appropriate now that school design changes from one based on a conceptual framework grounded in a productive-technical approach to one that considers wellbeing, pedagogy or 
community and includes all educational stakeholders. The weight of tradition both within the architectural profession and in the Spanish government regulation presents significant challenges for change, but there is growing recognition in Spain of the importance of meeting the needs of the school communities and including them in the design process. When the inhabitants of educational facilities are excluded from the design process, the site only represents the vision of the designers, educational managers and government.

\section{Local Input}

The project Hack the School (see website: http://bit.ly/2h3p2QY) emerged in a context where out-of-date regulations govern education and where learning communities are striving to take responsibility of their own spaces and to explore and develop new innovative pedagogies. In this regard, it is important to note that the project stands for the empowerment of schools by providing not only a set of resources and experiences but also by triggering a network of knowledge exchange among the different participant centres in Catalonia. This paper presents both the interrelated conceptual framework and implementation of the project, giving evidence of how learning by doing is one of the most effective ways to intervene and raise awareness about the potential of our current learning environments.

\section{Hack the School Open Challenge}

The Hack the School project funded and coordinated by the Jaume Bofill (JB) Foundation is set up as an open challenge for the transformation of educational spaces. All schools and high-schools in Catalonia are invited through a public open call and communications campaign coordinated by the JF Foundation. The idea is to "hack" one school space by developing a micro-project using the resources available for creating a prototype of the possible change. More than 170 schools and highschools responded to the call, and from those, 30 were selected to apply the Creative Toolkit (see Creative Toolkit: https://www.fbofill.cat/sites/default/files/Guia_hack theschool_200217.pdf; see website: http://bit.ly/2h3p2QY; see website: http://bit. ly/2fkQ9Dr) and participate in Hack the School activities organized by a committee of experts in the field of education and architecture. The JB Foundation also looked for volunteer architects and designers willing to participate in the call with the support of FAD (Fostering Arts \& Design-Design Hub Barcelona).

The project includes the following actions:

Introductory Workshop: An open free workshop organized to introduce the Creative Toolkit and the key concepts of the Hack the School framework, taking place at the Museum of Contemporary Art of Barcelona (MACBA). 
Matching Workshop: Selected schools and high-schools participate in a matching workshop where they meet their volunteer supporting architects and are introduced to the Hack the School Creative Toolkit and Process.

Hack the School Implementation: For three months each school and high-school autonomously apply the Creative Toolkit and participate in a range of activities. These include visits to other schools that had been previously transformed, workshops led by architect professionals and creativity workshops carried out in the Museum Centre of Arts Santa Mònica.

Social Media: The Creative Toolkit and JB Foundation promote the interaction among the participants. Moreover the Creative Toolkit aims to share the results of the key moments of the process.

Results \& Prizes: Each of the centres is asked to present a report on the results and two specific activities from the Toolkit; including the main aspects of the microproject developed and a reflection on the main learnings. The six best projects are recognized with awards and a final event is organized where all the centres have the opportunity to share ideas and projects.

\section{Reframing Innovative Learning Environments Through Wellbeing}

Hack the School utilises current regulations and constraints, and explores the possibilities to overcome them through creativity and co-design. The Creative Toolkit is designed to foster a series of micro-projects in the different school spaces using an interdisciplinary approach. The toolkit aims to help communities improve learning conviviality through a process that uses design-thinking techniques. The toolkit has three parts; a conceptual framework, methodological tips and the creative process itself based on a series of activities.

The conceptual framework is based on the three core aspects; wellbeing, environments and pedagogies. Often the understanding of innovative learning environments approaches the intersection of spaces, technologies and methodologies (Fig. 1).

However, as designers of the toolkit, we feel it is important to go one step further and reconsider this relationship by including a comprehensive conceptual framework that goes beyond the technicalities of each discipline (architecture and education). Using the umbrella of 'wellbeing' allows this, and drives reflection and performance towards a more holistic comprehension of the ILE. To support this framework, seven operational key criteria are included. The seven criteria-welcome, belonging, communication, cooperation, diversity, movement and transduction-serve to visualize the transformation possibilities of the spaces while enhancing a new culture of learning and community creation, widely promoting the global development of children and young people and providing a satisfactory and healthy working environment for the education professionals (Fig. 2). 
Fig. 1 Hack the school conceptual framework
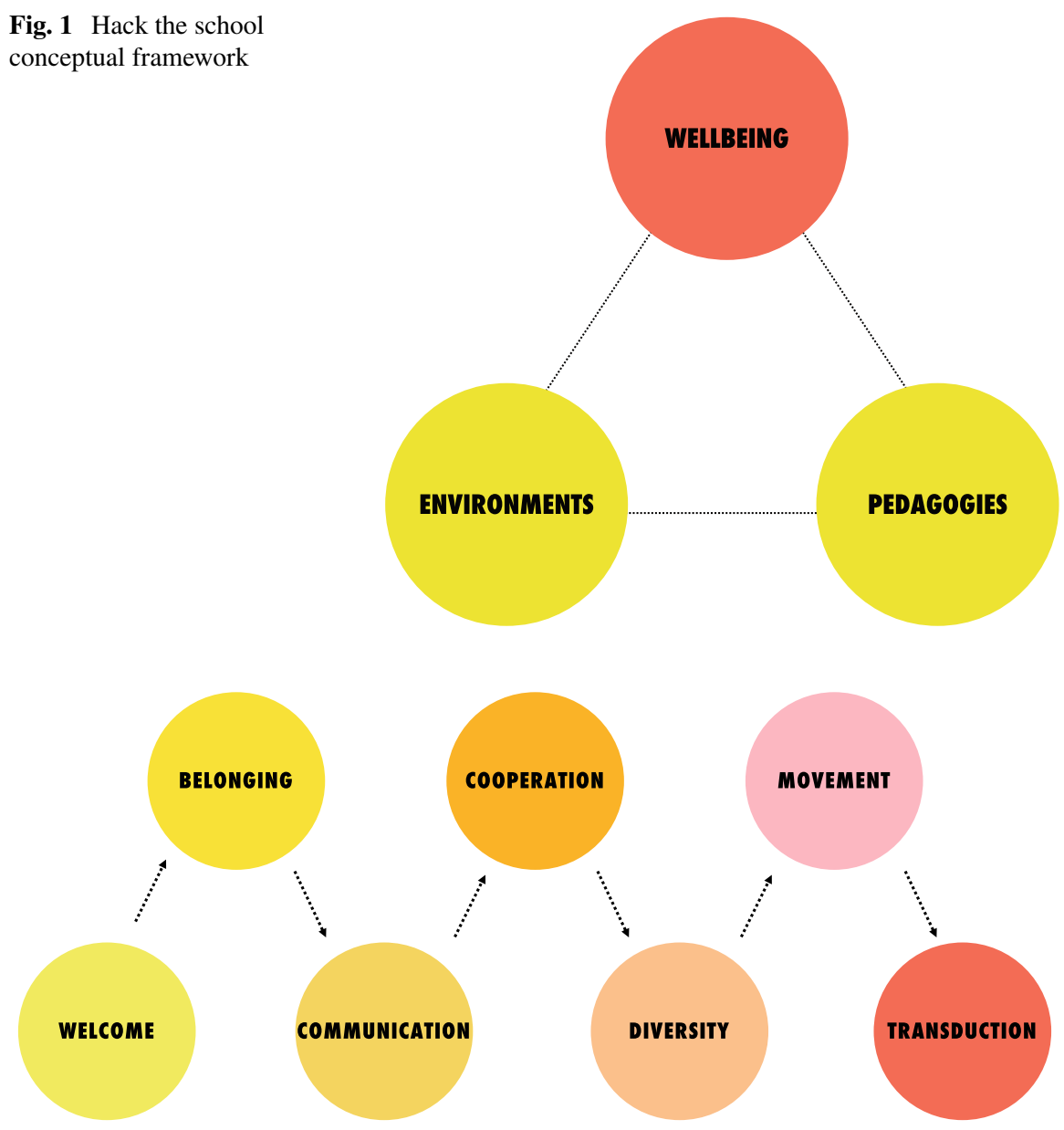

Fig. 2 Hack the school seven operational criteria

This framework serves to sustain the Hack the School process and the design of the Creative Toolkit and helps to foster changes that empower communities, so they can lead transformation on their own and attend to their particular needs. As said, the Creative Toolkit firstly explores the conceptualization and gives methodological tips to address learning environments transformation. It uses a design-thinking approach; its foundation is inherently practical. The toolkit does not aim to 'academically' educate communities, but rather fosters a learn-by-doing focus. The creative toolkit then presents a range of activities that are structured in four creative phases: Starting, Discovery, Co-creation and Assessment.

As Fig. 3 shows, the two first phases, Starting and Discovering, aim to create bonds and reflection among the members of the educational community, while the second focuses on the creation of the prototype and the implementation and assessment of 
CREATING-REFLECTING $\quad+$ CREATING-PROTOTYPING
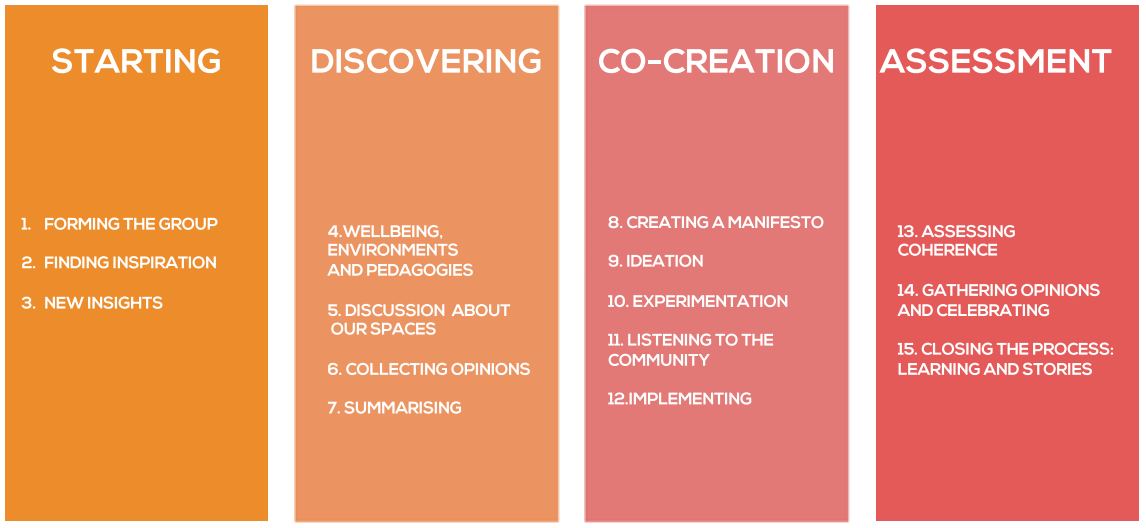

Fig. 3 Creative phases

it. The different activities aim to involve the entire community and widely integrate their interests and expectations, so the goals and outcomes become imagined, shared and celebrated by the whole community.

\section{Outcomes and Conclusions}

The outcomes of this project can be considered extremely positive. On one hand, all the centres selected participated actively in the different activities proposed throughout the process and shared on social media their questions ideas and progress. The use of the Creative Toolkit was uneven among communities, depending on their level of autonomy and experience in these kinds of processes. However, most of them stated that the Creative Toolkit guided the process and triggered inspiration to create and invent their own participatory activities, ways of working or sharing ideas. As the Farigola School stress in their final report, the comprehensive nature of the experience is one of the project's most valued aspects; including the conceptual approach, the process of implementation, the active participation of all the school community and the possibility to open and close a specific cycle of discovery and change. Hack the School has provided: a toolkit full of resources, tools and ideas, training, internal and external engagement through dissemination activities and motivation for involvement linked to the prize. Innovation has emerged in different ways and across groups and community members. In this regard, we can argue that the process served to overcome resistance to change and empower educational centres. 
Moreover, this change of attitude enhanced further changes in each school and highschool despite the limitations of law, and encouraged other centres to use the Creative Toolkit on their own.

\begin{abstract}
As a school we have always been very concerned about the concept of space and its distribution and aesthetics, as we have hoped for a warm and welcoming school for children and adults as they spend many hours daily. It is true that we have taken care of this aspect at a classroom level, looking for a shared approach but under the responsibility of each year tutor. Common spaces such as corridors, art classrooms, carpentry and dining room are always to be re-planned due to lack of time and human and economic resources. However, we were aware that they needed a change. The fact of participating in the Hack the School project opened a new interesting horizon of time and resources to be able to think how to face this change (Headmaster, Nou de Quart School).
\end{abstract}

For many schools, the call served as a motor for change; a way to address pending changes related to spaces transformation, but also to other aspects such as conviviality and the school's educational approach. In this regard, the relationship between the architects and the educational communities served to open discussion in the public sphere about established tradition and promoted an in-depth understanding of how educational methodologies and school spaces are the backbone when it comes to foster wellbeing. As one of the participant architects points out:

Participating in Hack the School appealed to me from different points of view. It has been an opportunity to learn and be able to share with others experiences and knowledge in the fields of education, design and art. Moreover, it is a project where you work with an intergenerational human team, and with professionals from different fields. The desire for new challenges and learning has led me to participate and get involved in this experience.

In the specific context of Catalonia, this fact links with the willingness of many teachers to change methods in order to accommodate diversity and experiment with innovative ways of learning. Implicitly, changing their spaces became the trigger to rethink education, including the implementation of new methodologies and the principles attached to those such as collaboration, horizontal learning and inclusiveness, those clearly related with the OECDs seven principles. It was also interesting how collateral educational topics emerged, such as gender issues; in some of the schools that worked on changing the playground, students raised gender issues regarding territory, privilege and diverse use needs.

\begin{abstract}
At a pedagogical level, I think it is important that we keep on reinforcing the collaborative group among students, taking into account gender issues too. When working in small mixed groups, often boys and girls felt frustrated. They stated the present of many stereotypes when it comes to play, considering sports something for boys and crafts more for girls. I think it is a good moment to incorporate a co-educational perspective, taking into account that the school is thinking in changing its methodology (Teacher comment).
\end{abstract}

The project reinforced communication and engagement at many levels; as some teachers mentioned, their students gave them ideas of how to become better educators, or how to provide ideas for experimentation. In this regard, the project helped leave behind a model based on single classroom education, and fostered a positive attitude 
of students towards the school. Some of the comments included: 'It has been so much fun'; 'what has surprised me the most is that we have been able to change the school and that we are going to be able to work properly in the future'; 'I have participated actively in this project because I wanted to help to change and improve our school'.

The project has seen strong commitment by students, indicating participation and autonomy have an impact on conviviality and the sense of belonging. Thus, the school was perceived as site full of possibilities and open to all. Now, any space can be used for educational purposes, in formal and informal ways. It was surprising to see how in a climate such as ours in Catalonia, schools did not use outdoor spaces which have been traditionally used only for play-time. This reconceptualization of the space had an impact on the school organization. In general, changes provided 'more sense' to the way teachers and families want to educate their children. One of the challenges is 'to unlearn the names for furniture and objects and see them for their characteristics and potentiality instead of their associated functionality', says one of the architects.

To conclude, the project can be understood as a facilitator of change, and its Creative Toolkit the strategic guide to make it effective. Of course, results did not follow a concrete pattern or standard; but the idea from the very beginning was to help participating schools and high-schools to find their own identity, using this space transformation as a trigger. Hack the School involved the creation of a stable space for reflection, discussion and contribution to the emerging educational issues, taking into account the equal and horizontal participation of teachers, families and students. In this regard, many of the participants stressed that besides the improvement of spaces, the project has had significant impact on communication as the project produced and reinforced channels of communication (social media, panels, meetings, etc.) among all the school community. As Canigó school reports the project enhanced 'the creation of a network, which has brought us together and has proved that together we can do more things and in a better way. Now families see that they can propose activities to the school'. Although the project focuses on the transformation of spaces, the schools agree on the fact that the process might be applied to other projects and topics. In general schools and high-schools valued the fact that the project had not only an impact on the school dynamics and life, but also the development of skills related to leadership and management among the students and among teachers and families - a shared empowerment.

One year after the experience, the JB Foundation did a review of the participating centres. In general, all the schools maintained the changes, totally or partially. On some occasions, the period of transformation of the spaces was considered a long term effort, which meant that they now expect to complete the project in three or four years. Other centres continue to involve families and students in the concretion of proposals, so changes respond to their needs. In this case the rhythm is slower though more participative-it reinforces the concept that good change is often a gradual, rather than immediate, action (Imms, 2018). As for the actors and their involvement, we see that more than half of the centres confirm that they have consolidated a group to work on additional tasks and that the call has been key to incorporating other stakeholders 
from the educational community that previously did not participate in the pedagogical debate. Hence, for the participating centres the project constituted the first milestone in the process of changing the school educational paradigm. This change marked a starting point in shared responsibility for the centre's educational performance and the importance of this among all the stakeholders. As one headmaster stressed, 'Hack the School has provided a collaborative working model in which each person brings the best of himself to achieve shared goals'. Hence, we might say that the 'Hack the School' experience allows us to say that although architectural regulations are restrictive and outdated in Spain, those 30 communities have been able to overcome them in only three months.

Acknowledgements Data utilized in this research was obtained in adherence to the required ethical protocol of the author's host institution. All images and diagrams are the property of the author, or the author has obtained consent to use them from the appropriate copyright owner.

\section{References}

Adell, J., \& Castañeda, L. (2012) Tecnologías emergentes? pedagogías emergentes. Tendencias emergentes en educación con TIC (pp. 13-32).

Departament dÉnsenyament. (2016). Criteris per a la construcció de nous edificis per a centres docents públics. Retrieved from http://ensenyament.gencat.cat/web/.content/home/departament/ publicacions/monografies/criteris-construccio-edificis-centres-publics/criteris_construccio_edi ficis_centres_docents_publics.pdf.

Fundació Jaume Bofill. (2017a). Hack the school - La veu dels protagonistes del canvi. Available from http://bit.ly/2h3p2QY.

Fundació Jaume Bofill. (2017b). Com dissenyar espais educatius per aprendre i conviure? Retrieved from https://www.fbofill.cat/sites/default/files/Guia_hacktheschool_200217.pdf.

Hanna, D., \& David, I. (2013). OECD (Eds.). The nature of learning: Using research to inspire practice, 2010. OECD Center for Educational Research and Innovation Ed. The nature of learning from the utilization of research to implementation. Tokyo: Akashi Publishing.

Imms, W. (2018). Innovative learning spaces: Catalysts/agents for change, or 'just another fad'? In S. Alterator \& C. Deed (Eds.), School space and its occupation: The conceptualisation and evaluation of new generation learning spaces (pp. 107-118). Amsterdam, The Netherlands: Sense Publishing.

Law $\mathrm{N}^{\circ} 34$. Boletín Oficial del Estado (Spain)1971.

Law No 14054. Boletín Oficial del Estado (Spain) 1978.

Law No 16419. Boletín Oficial del Estado (Spain) 1991.

Law No 4132. Boletín Oficial del Estad (Spain) 2010.

Silvia Sasot and Esther Belvis (Spain) are both professionals and university lecturers interested in the intersection between education, creativity, architecture and the arts. Silvia Sasot is an architect specialized in learning environments who works directly with school communities designing their spaces linked to their pedagogy. Esther Belvis is an art director and pedagogue who designs forefront strategies, crafts meaningful experiences, devises resilient content and designs disruptive action plans to inspire and boost social change. 
Open Access This chapter is licensed under the terms of the Creative Commons Attribution 4.0 International License (http://creativecommons.org/licenses/by/4.0/), which permits use, sharing, adaptation, distribution and reproduction in any medium or format, as long as you give appropriate credit to the original author(s) and the source, provide a link to the Creative Commons license and indicate if changes were made.

The images or other third party material in this chapter are included in the chapter's Creative Commons license, unless indicated otherwise in a credit line to the material. If material is not included in the chapter's Creative Commons license and your intended use is not permitted by statutory regulation or exceeds the permitted use, you will need to obtain permission directly from the copyright holder.

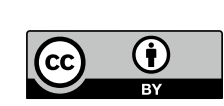

